\title{
A LEI DOS PARTIDOS POLÍTICOS E A REFORMA ELEITO- RAL: IMPACTO SOBRE A AVALIAÇÃO DE REGULARIDADE DAS CONTAS PRESTADAS À JUSTIÇA ELEITORAL
}

\section{Denise Goulart Schlickmann ${ }^{1}$}

\section{Introdução}

A reforma eleitoral introduzida pela Lei n. 13.165, de 29 de setembro de 2015, trouxe profundas alterações em três diplomas legais: o Código Eleitoral (Lei n. 4.737, de 15 de julho de 1965), a Lei dos Partidos Políticos (Lei n. 9.096, de 19 de setembro de 1995) e a Lei das Eleições (Lei n. 9.504, de 30 de setembro de 1997).

Este artigo visa a uma breve reflexão sobre as alterações que a reforma produziu sobre a Lei dos Partidos Políticos, especificamente no que se refere às regras de arrecadação, aplicação de recursos e prestação de contas à Justiça Eleitoral, abordando as modificações legislativas no contexto de seu impacto perante esse ramo de justiça especializada, a quem incumbe a avaliação de regularidade sobre as contas anualmente prestadas pelos partidos políticos.

Com a finalidade de melhor visualizar as modificações legislativas, compreendendo melhor a sua repercussão sobre o processo das contas partidárias, são elas agrupadas conforme adiante se examina neste artigo.

\section{a) Envio de balancetes mensais}

\section{Prescrevia o art. 32 da referida Lei:}

Art. 32. O partido está obrigado a enviar, anualmente, à Justiça Eleitoral, o balanço contábil do exercício findo, até o dia 30 de abril do ano seguinte.

\section{$[\ldots]$}

$\S 3^{\circ}$ No ano em que ocorrem eleições, o partido deve enviar balancetes mensais à Justiça Eleitoral, durante os quatro meses anteriores e os dois meses posteriores ao pleito.

A reforma eleitoral revoga o dispositivo e, via de consequência, extingue a obrigação de envio de balancetes mensais pelos partidos políticos à Justiça Eleitoral nos anos eleitorais. Referidos balancetes, após remetidos à Justiça Eleitoral, eram juntados aos autos das contas anuais para exame posterior. Isso porque a natureza contábil de tais demonstrativos 
não viabilizava o efetivo controle social a que visavam, razão pela qual a extinção não traz qualquer prejuízo ao processo.

Ademais, a movimentação havida nas campanhas eleitorais pelos partidos políticos é objeto, desde as eleições de 2010, de prestação de contas específica de campanha eleitoral, o que reduz significativamente a importância do encaminhamento dos referidos balancetes.

O tempestivo encaminhamento de informações a esse respeito à Justiça Eleitoral é suprido, de igual sorte, pela inovação operada pela mesma reforma eleitoral, mas agora em relação à Lei das Eleições (art. 28, § $4^{\circ}$ ), que fixa a obrigatoriedade de prestações de contas em 72 horas a respeito dos recursos financeiros recebidos, bem como de prestação de contas parcial em 15 de setembro, da qual devem constar informações ainda mais amplas.

\section{b) Desobrigação de prestação de contas}

\section{Art. $32[\ldots]$}

$\S 4^{\circ}$ Os órgãos partidários municipais, que não hajam movimentado recursos financeiros ou arrecadado bens estimáveis em dinheiro ficam desobrigados de prestar contas à Justiça Eleitoral, exigindose do responsável partidário, no prazo estipulado no caput, a apresentação de declaração da ausência de movimentação de recursos nesse período.

A inovação em destaque é, sem dúvida, prejudicial ao controle a ser exercido pela Justiça Eleitoral. Isto porque já há muito a jurisprudência eleitoral consagrou a máxima de que não é possível a um partido em funcionamento sobreviver sem arrecadar nenhuma espécie de recursos. Ainda que não haja a captação de recursos financeiros, a arrecadação de recursos estimáveis em dinheiro (bens e serviços) é minimamente necessária, de que é exemplo a cessão de imóvel para reuniões eventuais.

Assim, a mera declaração de ausência de movimentação de recursos certamente oculta à fiscalização a cessão - ainda que mínima - de bens e serviços estimáveis em dinheiro, hábeis a justificar a existência e o funcionamento partidários.

\section{c) Restrição à aplicação de sanções}

É em relação às sanções aplicáveis aos partidos políticos que a reforma eleitoral é mais incisiva e produz as alterações legislativas mais significativas, a começar pela inclusão do $\S 5^{\circ}$ ao art. 32 , in verbis: 
Art. 32 [...] § $5^{\circ} \mathrm{A}$ desaprovação da prestação de contas do partido não ensejará sanção alguma que o impeça de participar do pleito eleitoral.

A inserção de previsão expressa de que a desaprovação de contas não enseja sanção que impeça a participação no pleito eleitoral traduz medida legal evidentemente preventiva à eventual fixação de sanção desse jaez pela Justiça Eleitoral, de que é exemplo a novel suspensão de anotação do partido político (sanção prevista na Resolução TSE n. 23.432/ 14 para a hipótese de omissão de prestação de contas).

Igualmente restringindo a aplicação de sanções, a reforma eleitoral alterou diversos dispositivos do art. 37, iniciando-se pelo caput, nos termos abaixo consignados:

\begin{tabular}{|c|c|}
\hline Redação original & $\begin{array}{l}\text { Alteração decorrente da reforma } \\
\text { eleitoral }\end{array}$ \\
\hline $\begin{array}{l}\text { Art. 37. A falta de prestação de } \\
\text { contas ou sua desaprovação } \\
\text { total ou parcial implica a } \\
\text { suspensão de novas quotas do } \\
\text { fundo partidário e sujeita os } \\
\text { responsáveis às penas da lei, } \\
\text { cabíveis na espécie, aplicado } \\
\text { também o disposto no art. } 28 \text {. }\end{array}$ & $\begin{array}{l}\text { Art. 37. A desaprovação das } \\
\text { contas do partido implicará } \\
\text { exclusivamente a sanção de } \\
\text { devolução da importância } \\
\text { apontada como irregular, } \\
\text { acrescida de multa de até } 20 \% \\
\text { (vinte por cento). }\end{array}$ \\
\hline
\end{tabular}

A reforma passa a dispor que a sanção decorrente de desaprovação de contas não mais suspenda o recebimento de recursos do Fundo Partidário, mas unicamente determine a devolução do valor considerado irregular nas contas prestadas, acrescido de multa de até $20 \%$.

Verifica-se significativa alteração, no mérito, no que diz respeito às sanções, diminuindo-as consideravelmente, pois a devolução de recursos do Fundo Partidário tidos por irregulares ou não comprovados, dada sua natureza pública, já se impunha de qualquer sorte.

Exclui-se ainda do texto a sujeição dos responsáveis às penas da lei e, ainda, à possibilidade de cancelamento do registro civil e do estatuto partidários (penalidade aplicável apenas no âmbito nacional pelo Tribunal Superior Eleitoral), reduzindo sensivelmente as sanções aplicáveis.

Por óbvio, a mera exclusão do texto da sujeição dos responsáveis à responsabilidade pessoal não exclui a possibilidade de que a Justiça Eleitoral, constatando indícios ou provas de crimes, sejam eleitorais ou 
comuns, ou, ainda, de infrações de natureza administrativa ou tributária proceda à sua apuração ou os encaminhe às autoridades competentes para que o façam.

E a reforma trata de referir-se, no $\S 13$, introduzido ao mesmo artigo, expressamente à responsabilização de dirigentes, dispondo:

$\S 13$ A responsabilização pessoal civil e criminal dos dirigentes partidários decorrente da desaprovação das contas partidárias e de atos ilícitos atribuídos ao partido político somente ocorrerá se verificada irregularidade grave e insanável resultante de conduta dolosa que importe enriquecimento ilícito e lesão ao patrimônio do partido político.

O novo dispositivo vem corrigir, em parte, a alteração verificada no caput que poderia induzir, em uma leitura isolada do dispositivo, à exclusão de responsabilidade pessoal dos dirigentes, o que se viu não ser possível.

Contudo, à responsabilidade pessoal prevista em outros diplomas legais, antes referida, a lei vem acrescer importantes restrições, que dificultarão a sua aplicação: essa só restará caracterizada se estiverem presentes quatro requisitos, a serem verificados concomitantemente: (1) a irregularidade deve ser grave e insanável; (2) a conduta que a ela der causa deve ser dolosa; (3) há que se verificar enriquecimento ilícito; (4) deve estar caracterizada lesão ao patrimônio do partido.

Ainda no que diz respeito às sanções, importante alteração verificase no $\S 2^{\circ}$ do mesmo artigo:

\begin{tabular}{|l|l|}
\hline Redação original & $\begin{array}{l}\text { Alteração decorrente da reforma } \\
\text { eleitoral }\end{array}$ \\
\hline $\begin{array}{l}\text { § } 2^{\circ} \text { A sanção a que se refere o } \\
\text { caput será aplicada } \\
\text { exclusivamente à esfera } \\
\text { partidária responsável pela } \\
\text { irregularidade. }\end{array}$ & $\begin{array}{l}\text { § } 2^{\circ} \text { A sanção a que se refere o } \\
\text { caput será aplicada } \\
\text { exclusivamente à esfera } \\
\text { partidária responsável pela } \\
\text { irregularidade, não suspendendo } \\
\text { o registro ou a anotação de seus } \\
\text { órgãos de direção partidária } \\
\text { nem tornando devedores ou } \\
\text { inadimplentes os respectivos } \\
\text { responsáveis partidários. }\end{array}$ \\
\hline
\end{tabular}


A alteração operada neste dispositivo é, de igual sorte, clara reação mas, na prática, apenas de caráter preventivo - à regulamentação expedida pela Justiça Eleitoral na Resolução TSE n. 23.432/14, que previu a suspensão de registro (na hipótese do diretório nacional) ou de anotação (na hipótese dos diretórios estadual ou municipal) e ao registro de inadimplência dos responsáveis quando verificada a omissão no dever de prestar contas, embora, veja-se, aquela penalidade refira-se exclusivamente à omissão no dever de prestar contas e jamais à sua desaprovação.

Frise-se: a sanção disposta pela Justiça Eleitoral referiu-se apenas à omissão no dever de prestar contas e, nessa condição, poderia ser suspensa a qualquer tempo, bastando a prestação das contas e o caput, conforme se registrou, não mais se refere à omissão na prestação de contas, mas apenas e tão somente à desaprovação, pelo que a nova redação não exercerá os efeitos aparentemente pretendidos pela reforma, permanecendo legítima a previsão da sanção disposta pela Justiça eleitoral, eis que sobre este fato (omissão) nada mais dispõe o caput (a omissão passa a ser regulada, após a reforma eleitoral, em dispositivo específico, o art. 37-A).

$E$ prossegue a reforma eleitoral no que diz respeito às sanções, no mesmo artigo:

\begin{tabular}{|c|c|}
\hline Redação original & $\begin{array}{l}\text { Alteração decorrente da reforma } \\
\text { eleitoral }\end{array}$ \\
\hline $\begin{array}{l}\S 3^{\circ} \text { A sanção de suspensão do } \\
\text { repasse de novas quotas do } \\
\text { Fundo Partidário, por } \\
\text { desaprovação total ou parcial da } \\
\text { prestação de contas de partido, } \\
\text { deverá ser aplicada de forma } \\
\text { proporcional e razoável, pelo } \\
\text { período de } 1 \text { (um) mês a } 12 \\
\text { (doze) meses, ou por meio do } \\
\text { desconto, do valor a ser } \\
\text { repassado, da importância } \\
\text { apontada como irregular, não } \\
\text { podendo ser aplicada a sanção } \\
\text { de suspensão, caso a prestação } \\
\text { de contas não seja julgada, pelo } \\
\text { juízo ou tribunal competente, } \\
\text { após } 5 \text { (cinco) anos de sua } \\
\text { apresentação. }\end{array}$ & $\begin{array}{l}\text { § } 3^{\circ} \text { A sanção a que se refere o } \\
\text { caput deverá ser aplicada de } \\
\text { forma proporcional e razoável, } \\
\text { pelo período de } 1 \text { (um) a } 12 \\
\text { (doze) meses, e o pagamento } \\
\text { deverá ser feito por meio de } \\
\text { desconto nos futuros repasses } \\
\text { de quotas do Fundo Partidário, } \\
\text { desde que a prestação de } \\
\text { contas seja julgada, pelo juízo ou } \\
\text { tribunal competente, em até } 5 \\
\text { (cinco) anos de sua } \\
\text { apresentação. }\end{array}$ \\
\hline
\end{tabular}


Aqui, uma vez mais, minimizam-se as consequências da desaprovação de contas. Não havendo mais a suspensão do recebimento de futuras quotas do Fundo Partidário na hipótese de desaprovação, a lei passa a prever que a sanção se dê pelo desconto nos futuros repasses que seriam de direito do partido político apenado.

Ora, não há regra legal a respeito da distribuição dos recursos do Fundo Partidário no âmbito interno das agremiações. A lei limita-se a estabelecer critérios para a distribuição dos recursos do Tesouro Nacional para os diretórios nacionais. Os únicos critérios a serem observados para a distribuição dos recursos do Fundo Partidário entre diretórios nacional, estaduais e municipais são aqueles previstos no próprio estatuto partidário, ou seja, estabelecidos pelo próprio partido político. Não há que se falar, pois, previamente, de recursos devidos sobre os quais incidiria o suposto desconto.

Assim, vê-se que esta penalidade - de desconto - é efetivamente aplicável, pela natureza de sanção, apenas ao diretório nacional, que recebe recursos de terceiro (do Tribunal Superior Eleitoral). A todas as instâncias inferiores, sempre será possível prever repasse irreal para dele deduzir sanção aplicada, que incidirá sobre recursos que jamais seriam, na prática, transferidos à agremiação, o que culmina por retirar completamente o efeito da sanção.

$\mathrm{E}$ a reforma eleitoral acresce à regulamentação do desconto o que dispõe o $\S 9^{\circ}$ :

$\S 9^{\circ} \mathrm{O}$ desconto no repasse de quotas resultante da aplicação da sanção a que se refere o caput será suspenso durante o segundo semestre do ano em que se realizarem as eleições.

Como se já não fosse deletéria a sanção do desconto, como antes se viu, a penalidade - única possível pelo novo ordenamento - não será aplicável no segundo semestre do ano em que se realizam eleições, claramente viabilizando que tais recursos cheguem às campanhas eleitorais.

Por fim, no que se refere às sanções, a reforma eleitoral passa a disciplinar a sanção a ser aplicada na hipótese de omissão na obrigação de prestar contas em dispositivo separado, conforme abaixo:

Art. 37-A. A falta de prestação de contas implicará a suspensão de novas cotas do Fundo Partidário enquanto perdurar a inadimplência e sujeitará os responsáveis às penas da lei.

Não há, pois, inovações quanto às sanções aplicáveis para a omissão no dever de prestar contas, que passam a ser previstas em dispositivo isolado. 


\section{d) Delimitação de competência da Justiça Eleitoral}

Art. 34. A Justiça Eleitoral exerce a fiscalização sobre a prestação de contas do partido e das despesas de campanha eleitoral, devendo atestar se elas refletem adequadamente a real movimentação financeira, os dispêndios e recursos aplicados nas campanhas eleitorais, exigindo a observação das seguintes normas:

Importante inovação há de ser destacada neste dispositivo, qual seja, a exclusão dentre as competências da Justiça Eleitoral daquela de fiscalização da escrituração contábil.

Em boa hora, a inovação permite que a Justiça Eleitoral concentre suas atividades de fiscalização sobre o cumprimento das obrigações de natureza eleitoral, otimizando seus recursos e resultados.

As obrigações de natureza contábil, a serem cumpridas pelos partidos políticos, inserem-se em rol de obrigações comuns, para as quais o ordenamento jurídico já prevê ações de fiscalização específica pelos órgãos fazendários e de classe.

Com o mesmo objetivo, em razão da exclusão da competência de fiscalização contábil, a reforma eleitoral alterou a redação do inciso III do mesmo artigo, conforme verifica-se abaixo:

\begin{tabular}{|c|c|}
\hline Redação original & $\begin{array}{l}\text { Alteração decorrente da reforma } \\
\text { eleitoral }\end{array}$ \\
\hline $\begin{array}{l}\text { III - escrituração contábil, com } \\
\text { documentação que comprove a } \\
\text { entrada e saída de dinheiro ou } \\
\text { de bens recebidos e aplicados; }\end{array}$ & $\begin{array}{l}\text { III - relatório financeiro, com } \\
\text { documentação que comprove a } \\
\text { entrada e saída de dinheiro ou } \\
\text { de bens recebidos e aplicados; }\end{array}$ \\
\hline
\end{tabular}

\section{e) Comprovação de gastos}

A reforma eleitoral acresce ao art. 37 o $\S 10$, que regulamenta a comprovação de gastos com passagens aéreas nos seguintes termos:

$\S 10$. Os gastos com passagens aéreas serão comprovados mediante a apresentação da fatura ou duplicata emitida por agência de viagem, quando for o caso, desde que informados os beneficiários, as datas e os itinerários, vedada a exigência de apresentação de qualquer outro documento para esse fim. 
A inovação, neste aspecto, é também clara reação à regulamentação expedida pela Justiça Eleitoral para essa finalidade, que exigia, para esse tipo de despesas, a comprovação por documentos adicionais.

Nesse aspecto, é importante observar que as regras de comprovação de despesas devem ser uníssonas para quaisquer gastos eleitorais, fundadas nas exigências fiscais de comprovação, sob pena de particularizar-se pela especificidade do gasto a sua forma de comprovação também na via normativa, o que demonstra ser tarefa hercúlea e com poucas chances de abarcar todas as particularidades existentes.

\section{f) Ampliação do prazo para juntada de documentos}

Sem dúvida, uma das alterações mais deletérias operadas pela reforma eleitoral é aquela disposta no novo § 11 do art. 37, litteris:

$\S$ 11. Os órgãos partidários poderão apresentar documentos hábeis para esclarecer questionamentos da Justiça Eleitoral ou para sanear irregularidades a qualquer tempo enquanto não transitada em julgado a decisão que julgar a prestação de contas.

Grave inserção legislativa, o parágrafo em comento culmina por descaracterizar a natureza judicial da prestação de contas.

Uma vez proferida decisão pela Justiça Eleitoral, sendo o processo judicial, ao partido político insatisfeito com o decisum compete ingressar com um dos remédios jurídicos previstos no sistema processual (recurso stricto sensu e embargos de declaração, v.g.).

A infinda possibilidade de juntar documentos a qualquer tempo enquanto não transitada em julgado a decisão descaracteriza por completo a natureza judicial das contas, permitindo um eterno refazer de contas até que sejam aprovadas. Será possível, por exemplo, a juntada de documentos onde a lei não permitiria (recursos especial, v.g.) ou mesmo fazer chegar contas de diretórios municipais até o Tribunal Superior Eleitoral acrescendo documentos que por este seriam examinados? O procedimento seria in totum contrário ao próprio disciplinamento dos recursos na Corte Superior.

É o que parece que a lei pretende permitir. Não vencido o prazo recursal, ou seja, dentro do tríduo, pode-se juntar documentos a qualquer tempo. E na literalidade da norma, sempre que tais documentos forem analisados geram uma nova decisão, também recorrível, à qual podem ser juntados novos documentos. A inserção é, pois, extremamente prejudicial ao pro- 
cesso e retardará de forma muito significativa a decisão definitiva sobre as contas.

\section{g) Hipótese de impossibilidade de desaprovação das contas}

Ao mesmo art. 37, a reforma eleitoral acresceu o § 12, que dispõe:

$\S 12$. Erros formais ou materiais que no conjunto da prestação de contas não comprometam o conhecimento da origem das receitas e a destinação das despesas não acarretarão a desaprovação das contas.

Dispositivo muito similar vigora na Lei das Eleições, sendo agora transposto para a Lei dos Partidos Políticos, buscando delimitar e cercear o julgamento de regularidade sobre as contas que incumbe à Justiça Eleitoral. Ora, por certo, o dispositivo contraria um dos princípios basilares do direito, que consagra a livre apreciação da prova e o convencimento motivado do julgador, impondo-lhe parâmetros restritos à desaprovação.

\section{h) Repercussão da desaprovação de contas sobre a fundação par- tidária}

A reforma eleitoral introduz ao mesmo art. 37, novo parágrafo, que dispõe:

$\S 14$. O instituto ou fundação de pesquisa e de doutrinação e educação política não será atingido pela sanção aplicada ao partido político em caso de desaprovação de suas contas, exceto se tiver diretamente dado causa à reprovação.

O novo dispositivo garante que o repasse de recursos do Fundo Partidário à fundação partidária não seja afetado pela desaprovação de contas daquele, salvo se houver responsabilidade da própria fundação. A inovação certamente resulta do procedimento de inclusão dos gastos realizados pela fundação na prestação de contas do partido político, inovação da Resolução TSE n. 23.432/14, que passa a integrar as contas da fundação àquelas prestadas pelo partido e julgadas pelo Tribunal Superior Eleitoral.

\section{i) Disciplinamento dos requisitos para a arrecadação de recursos}

A reforma eleitoral alterou o $\S 3^{\circ}$ do art. 39 , que passou a dispor conforme segue: 


\begin{tabular}{|c|c|}
\hline Redação original & $\begin{array}{l}\text { Alteração decorrente da reforma } \\
\text { eleitoral }\end{array}$ \\
\hline $\begin{array}{l}\text { Art. } 39 \text { [...] } \S 3^{\circ} \text { As doações em } \\
\text { recursos financeiros devem ser, } \\
\text { obrigatoriamente, efetuadas por } \\
\text { cheque cruzado em nome do } \\
\text { partido político ou por depósito } \\
\text { bancário diretamente na conta } \\
\text { do partido político }\end{array}$ & $\begin{array}{l}\text { Art. } 39[\ldots] \text { [..] } 3^{\circ} \text { As doações de } \\
\text { recursos financeiros somente } \\
\text { poderão ser efetuadas na conta } \\
\text { do partido político por meio de: } \\
\text { I - cheques cruzados e nominais } \\
\text { ou transferência eletrônica de } \\
\text { depósitos; } \\
\text { II - depósitos em espécie } \\
\text { devidamente identificados; } \\
\text { III - mecanismo disponível em } \\
\text { sítio do partido na internet, } \\
\text { permitindo inclusive o uso de } \\
\text { cartão de crédito ou de débito, e } \\
\text { que atenda aos seguintes } \\
\text { requisitos:identificados; } \\
\text { III - mecanismo disponível em } \\
\text { sítio do partido na internet, } \\
\text { permitindo inclusive o uso de } \\
\text { cartão de crédito ou de débito, e } \\
\text { que atenda aos seguintes } \\
\text { requisitos: identificados; } \\
\text { III - mecanismo disponível em } \\
\text { sítio do partido na internet, } \\
\text { permitindo inclusive o uso de } \\
\text { cartão de crédito ou de débito, e } \\
\text { que atenda aos seguintes } \\
\text { requisitos: } \\
\text { a) identificação do doador; } \\
\text { b) emissão obrigatória de recibo } \\
\text { eleitoral para cada doação } \\
\text { realizada. } \\
\text { [....] }\end{array}$ \\
\hline
\end{tabular}

A alteração disciplina de forma mais didática os requisitos para a arrecadação de recursos, em incisos específicos, transportando para a norma partidária requisitos regulamentados pela Justiça Eleitoral para as eleições.

Em que pese a sabida intenção da reforma eleitoral de tornar clara a redação para exigir para todas as doações, independentemente da espécie, a emissão de recibos (eis que os extratos eletrônicos de contas bancárias nem sempre possibilitam tal verificação e não são 
disponibilizados integralmente a tempo de proceder-se o exame das contas de candidatos eleitos, por exemplo), a redação que exige a emissão de recibo eleitoral para todas as doações restou alocada em alínea pertencente a inciso que trata de arrecadação de recursos pela internet.

A Justiça Eleitoral precisará promover interpretação sistêmica da norma ou regulamentação específica para que produza efeitos para todas as doações auferidas.

\section{j) Alteração nos parâmetros para distribuição do Fundo Partidário}

\begin{tabular}{|l|l|}
\hline Redação original & $\begin{array}{l}\text { Alteração decorrente da reforma } \\
\text { eleitoral }\end{array}$ \\
\hline Art. 41-A. Do total do Fundo & Art. 41-A. Do total do Fundo \\
Partidário: [...] & Partidário: [...] \\
I- $5 \%$ (cinco por cento) serão & I- $5 \%$ (cinco por cento) serão \\
destacados para entrega, em & destacados para entrega, em \\
partes iguais, a todos os & partes iguais, a todos os \\
partidos que tenham seus & partidos que atendam aos \\
estatutos registrados no Tribunal & requisitos constitucionais de \\
Superior Eleitoral; e & acesso aos recursos do Fundo \\
& Partidário; e \\
\hline
\end{tabular}

A reforma eleitoral implementou requisitos adicionais para acesso aos recursos do Fundo Partidário, cuja exigência de cumprimento foi integrada à norma:

Art. $7^{\circ} \mathrm{O}$ partido político, após adquirir personalidade jurídica na forma da lei civil, registra seu estatuto no Tribunal Superior Eleitoral.

$\S 1^{\circ}$ Só é admitido o registro do estatuto de partido político que tenha caráter nacional, considerando-se como tal aquele que comprove, no período de dois anos, o apoiamento de eleitores não filiados a partido político, correspondente a, pelo menos, 0,5\% (cinco décimos por cento) dos votos dados na última eleição geral para a Câmara dos Deputados, não computados os votos em branco e os nulos, distribuídos por um terço, ou mais, dos Estados, com um mínimo de $0,1 \%$ (um décimo por cento) do eleitorado que haja votado em cada um deles. (Redação dada pela Lei $n^{\circ} 13.165$, de 2015)

$\S 2^{\circ}$ Só o partido que tenha registrado seu estatuto no Tribunal Superior Eleitoral pode participar do processo eleitoral, receber recursos 
do Fundo Partidário e ter acesso gratuito ao rádio e à televisão, nos termos fixados nesta Lei.

$\S 3^{\circ}$ Somente o registro do estatuto do partido no Tribunal Superior Eleitoral assegura a exclusividade da sua denominação, sigla e símbolos, vedada a utilização, por outros partidos, de variações que venham a induzir a erro ou confusão. (grifou-se)

\section{I) Alteração das hipóteses de aplicação de recursos do Fundo Par- tidário}

A primeira importante alteração verificada nesse aspecto diz respeito às despesas com pessoal. Veja-se:

\begin{tabular}{|c|c|}
\hline Redação original & $\begin{array}{l}\text { Alteração decorrente da reforma } \\
\text { eleitoral }\end{array}$ \\
\hline $\begin{array}{l}\text { Art. 44. Os recursos oriundos do } \\
\text { Fundo Partidário serão } \\
\text { aplicados: } \\
\text { I - na manutenção das sedes e } \\
\text { serviços do partido, permitido o } \\
\text { pagamento de pessoal, a } \\
\text { qualquer título, observado neste } \\
\text { último caso o limite máximo de } \\
50 \% \text { (cinquenta por cento) do } \\
\text { total recebido. (Inciso com } \\
\text { redação dada pela Lei } n^{\circ} \\
12.034 \text {, de } 29 / 9 / 2009 \text { ) }\end{array}$ & $\begin{array}{l}\text { Art. 44. Os recursos oriundos do } \\
\text { Fundo Partidário serão } \\
\text { aplicados: } \\
\text { I - na manutenção das sedes e } \\
\text { serviços do partido, permitido o } \\
\text { pagamento de pessoal, a } \\
\text { qualquer título observado, do total } \\
\text { recebido, os seguintes limites: } \\
\text { a) } 50 \% \text { (cinquenta por cento) } \\
\text { para o órgão nacional; } \\
\text { b) } 60 \% \text { (sessenta por cento) } \\
\text { para cada órgão estadual e } \\
\text { municipal; }\end{array}$ \\
\hline
\end{tabular}

A reforma eleitoral produziu significativa alteração no dispositivo que trata da aplicação dos recursos com pessoal. De 50\%, percentual aplicável ao total recebido, independentemente da esfera de sua aplicação, passou a prever percentuais diferenciados conforme se tratar de órgão nacional (50\%) ou de estadual e municipal (60\%).

Assim, dos recursos recebidos em cada esfera hierarquicamente inferior, o percentual máximo de aplicação resta majorado para $60 \%$.

E prossegue, no mesmo artigo: 


\begin{tabular}{|c|c|}
\hline Redação original & $\begin{array}{l}\text { Alteração decorrente da reforma } \\
\text { eleitoral }\end{array}$ \\
\hline $\begin{array}{l}\text { V - na criação e manutenção de } \\
\text { programas de promoção e } \\
\text { difusão da participação política } \\
\text { das mulheres conforme } \\
\text { percentual que será fixado pelo } \\
\text { órgão nacional de direção } \\
\text { partidária, observado o mínimo } \\
\text { de } 5 \% \text { (cinco por cento) do total. }\end{array}$ & $\begin{array}{l}\text { V - na criação e manutenção de } \\
\text { programas de promoção e } \\
\text { difusão da participação política } \\
\text { das mulheres, criados e } \\
\text { mantidos pela secretaria da } \\
\text { mulher do respectivo partido } \\
\text { político ou, inexistindo a } \\
\text { secretaria, pelo instituto ou } \\
\text { fundação de pesquisa e de } \\
\text { doutrinação e educação política } \\
\text { de que trata o inciso } \mathrm{N} \text {, } \\
\text { conforme percentual que será } \\
\text { fixado pelo órgão nacional de } \\
\text { direção partidária, observado o } \\
\text { mínimo de 5\% (cinco por cento) } \\
\text { do total; }\end{array}$ \\
\hline
\end{tabular}

A reforma eleitoral passa a disciplinar de forma mais detalhada a despesa com a criação e manutenção de programas destinados à participação política de mulheres, regulamentando a competência pela sua criação e passando a dispor que o percentual a ser aplicado será fixado pelo órgão nacional, não inferior a 5\%, como antes estabelecido.

As alterações legislativas modificam ainda de forma mais substancial essa hipótese de aplicação,

\begin{tabular}{|l|l|}
\hline Redação original & $\begin{array}{l}\text { Alteração decorrente da reforma } \\
\text { eleitoral }\end{array}$ \\
\hline $\begin{array}{l}\text { § 5 O partido que não cumprir o } \\
\text { disposto no inciso V do caput } \\
\text { deste artigo deverá, no ano } \\
\text { subsequente, acrescer o }\end{array}$ & $\begin{array}{l}\text { § } 5^{\circ} \text { O partido político que não } \\
\text { cumprir o disposto no inciso V } \\
\text { do caput deverá transferir o } \\
\text { percentual de 2,5\% (dois inteiros } \\
\text { saldo para conta específica, } \\
\text { sendo vedada sua aplicação } \\
\text { para finalidade diversa, de modo } \\
\text { Fundo Partimos por cento) do } \\
\text { destinação, ficando essaldo remanescente } \\
\text { utilizá-lo para finalidade diversa. } \\
\text { deverá ser aplicado dentro do } \\
\text { exercício financeiro subsequente, } \\
\text { sob pena de acréscimo de } \\
12,5 \% \text { (doze inteiros e cinco } \\
\text { décimos por cento) do valor } \\
\text { previsto no inciso V do caput, a } \\
\text { ser aplicado na mesma } \\
\text { finalidade. }\end{array}$ \\
\hline
\end{tabular}


A reforma disciplina procedimento mais específico e que fortalece o controle da aplicação dos recursos do Fundo Partidário nos programas destinados à participação política de mulheres, obrigando à transferência dos recursos destinados a essa aplicação - quando não efetivada no exercício - a conta específica que garanta a sua aplicação no exercício subsequente.

Altera-se, igualmente, percentual e forma de cálculo da sanção pelo inadimplemento: se antes era de percentual específico (2,5\%) a ser aplicado sobre o valor do Fundo Partidário recebido, agora passa a ser de $12,5 \%$ a ser aplicado sobre o valor inicialmente previsto (5\%).

\section{E a lei passa a dispor:}

$\S 5^{\circ}$-A A critério das agremiações partidárias, os recursos a que se refere $\mathrm{o}$ inciso $\mathrm{V}$ poderão ser acumulados em diferentes exercícios financeiros, mantidos em contas bancárias específicas, para utilização futura em campanhas eleitorais de candidatas do partido.

A reforma introduz alternativa à aplicação desses mesmos recursos, consistente na reserva do montante legal em conta específica para aplicação futura em campanhas eleitorais de candidatas do partido.

A comprovação de aplicação seria realizada, no exercício em exame, pelo depósito na conta de reserva, gerando a obrigação de futura aplicação, a ser fiscalizada pela Justiça Eleitoral.

E, por fim, ainda quanto a este dispositivo, passa a prever a Lei dos Partidos Políticos:

$\S 7^{\circ} \mathrm{A}$ critério da secretaria da mulher ou, inexistindo a secretaria, a critério da fundação de pesquisa e de doutrinação e educação políti$c a$, os recursos a que se refere o inciso $V$ do caput poderão ser acumulados em diferentes exercícios financeiros, mantidos em contas bancárias específicas, para utilização futura em campanhas eleitorais de candidatas do partido, não se aplicando, neste caso, o disposto no $\S 5^{\circ}$.

Aqui a norma repete a mesma prerrogativa do parágrafo anterior, agora voltada à secretaria da mulher ou fundação.

Destaque-se, ainda, que às hipóteses legalmente previstas para aplicação de recursos do Fundo Partidário, a reforma eleitoral acresce:

VI - no pagamento de mensalidades, anuidades e congêneres devidos a organismos partidários internacionais que se destinem ao apoio à pesquisa, ao estudo e à doutrinação política, aos quais seja o partido político regularmente filiado. 
A reforma cria nova hipótese de aplicação de recursos do Fundo Partidário, vinculada à comprovação de filiação regular.

E, por fim:

VII - no pagamento de despesas com alimentação, incluindo restaurantes e lanchonetes.

De igual sorte, disciplina hipótese adicional, voltada especificamente à alimentação, nada dispondo sobre a necessidade de vincular-se tais despesas às atividades regulares da agremiação, o que precisará ser objeto de regulamentação pela Justiça Eleitoral (não raras vezes, se impôs devolução de recursos dessa natureza, por restar ausente tal comprovação).

\section{Conclusão}

A Lei n. 13.165/15 produziu importantes inovações no que diz respeito à matéria da arrecadação de recursos, despesas e prestação de contas dos partidos políticos à Justiça Eleitoral.

Ao tempo em que produziu alterações sem grande impacto, de que são exemplos a desobrigação de envio de balancetes mensais pelos partidos políticos à Justiça Eleitoral; o disciplinamento da comprovação de gastos com passagens aéreas; a prescrição de hipótese de impossibilidade de desaprovação de contas quando houver determinada espécie de erros; a impossibilidade de que haja repercussão na fundação partidária de sanção aplicada ao partido; o disciplinamento didático de regras já estabelecidas pela Justiça Eleitoral para a arrecadação de recursos, trouxe ao mundo jurídico outras de grande repercussão.

É o caso da desobrigação da prestação de contas em circunstâncias em que o partido declare não haver movimentação de recursos; do implemento de diversas restrições à aplicação de sanções por desaprovação de contas, reduzindo-as sensivelmente e alterando-lhes a natureza e da ampliação infinda do prazo para juntada de novos documentos a contas que não tenham transitado em julgado, que prorrogará no tempo indefinidamente a prolação de decisões definitivas sobre sua regularidade. A reforma eleitoral instituiu, ainda, novas hipóteses de aplicação dos recursos do Fundo Partidário.

Aspecto positivo merece relevo, ao retirar-se a competência de fiscalização contábil das contas partidárias da Justiça Eleitoral, permitindo que esta se dedique exclusivamente ao exame de regularidade que de fato lhe incumbe, centrado nas obrigações de natureza eleitoral. 
Ao fim e ao cabo, pode-se concluir que as alterações são profundas e impactarão seriamente o processo de prestação de contas partidária à Justiça Eleitoral. O tempo dirá quais as consequências a reforma ora implementada trará ao processo democrático brasileiro. É certo afirmar, contudo, que se inaugura um tempo de profundas alterações também nas normas regulamentares, infralegais, ao encargo da Justiça Eleitoral sobre a matéria. Seja para dar-lhes interpretação sistêmica, seja para recompor os sistemas de controle que permitem o juízo de regularidade que se impõe a essa justiça se façam sobre as contas.

\section{Referências}

BRASIL. Lei 9.096, de 19.09.1995. Dispõe sobre partidos políticos, regulamenta os arts. 17 e 14, § $3^{\circ}$, inciso V, da Constituição Federal. Diário Oficial da República Federativa do Brasil, Brasília, DF, 20.09.1995. Seção 1, p. 14.545 a 15549.

Lei 13.165 , de 29.09.2015. Altera as Leis nos 9.504, de 30 de setembro de 1997, 9.096, de 19 de setembro de 1995, e 4.737, de 15 de julho de 1965 - Código Eleitoral, para reduzir os custos das campanhas eleitorais, simplificar a administração dos Partidos Políticos e incentivar a participação feminina. Diário Oficial da República Federativa do Brasil, Brasília, DF, 2909.2015. Seção 1, p. 1 a 5.

\section{Notas}

${ }^{1}$ Coordenadora de Controle Interno do Tribunal Regional Eleitoral de Santa Catarina, integrante dos grupos de estudo formados pelo Tribunal Superior Eleitoral para minutar as normas sobre arrecadação, aplicação de recursos e prestação de contas à Justiça Eleitoral, graduada em Ciências Econômicas, Ciências Contábeis e Direito pela Universidade Federal de Santa Catarina. Pós-graduada em Auditoria Governamental pela Universidade Federal de Santa Catarina e em Direito Eleitoral pela Universidade do Vale do Itajaí. 